\title{
Gestão territorial em Unidades de Conservação de Uso Sustentável e incoerências no SNUC
}

\section{The managment territorial in the sustainable use Conservation Units and the incoherence in SNUC}

Catherine Prost - Doutora em Geopolítica pela Universidade Paris 8, Paris, França. Professora Associada I da Universidade Federal da Bahia. Trabalha na linha de pesquisa Manejo comunitário dos recursos naturais. E-mail: cprost@ufba.br

Mário Alberto dos Santos - Professor Assistente I da Universidade Federal do Oeste da Bahia, Doutorando em Geografia na Linha de Pesquisa Planejamento e gestão comunitária do território. E-mail: mario.alberto@ufob.edu.br

\section{Resumo}

Este artigo analisa o modelo de gestão estabelecido pelo Estado brasileiro para as UCUS. Tais territórios, que são usufruídos pelas populações tradicionais agroextrativistas, apresentam estrutura jurídica construída desde a década de 1980 e que cria diretrizes e princípios para sua gestão. As atividades do Grupo de Pesquisa Costeiros vinculado ao programa de Pós-Graduação em Geografia da UFBA foram essenciais para as conclusões aqui apresentadas. Reflexões que consideram a relevância das geograficidades locais para $\mathrm{O}$ entendimento da organização do tecido social e das ações políticas para a gestão das UCUS. Tem-se no diálogo e na autonomia fenômenos sociais intimamente ligados às práticas da ação política, essencial às transformações necessárias no atual modelo de cogestão para um modelo de autogestão. Esse processo de construção social e política não prescinde da parceria do Estado, o que se questiona é a necessidade de uma parceria emancipatória e não de controle territorial e/ou ideológico.

\begin{abstract}
Reflected in that article about the management model established by the Brazilian State for UCUS. Such territories, which are enjoyed by traditional populations agroextractivist, presents legal structure built since the 1980 and establishing guidelines and principles for its management. The activities of the Costeiros Research Group linked to the Post-graduate program in UFBA Geography were essential to the conclusions presented here. Reflections consider the relevance of local geograficidades for understanding the organization of the social fabric and political actions for the management of UCUS. It has been on dialogue and autonomy social phenomenon of political action practices closely linked, essential to the changes needed in the current model of co-management for a self-management model. This process of social and political construction can not do without the state association, which we question is the need for an emancipatory association and not territorial control and/or ideological.
\end{abstract}

\section{Palavras-chave}

Autonomia. Diálogo. Geograficidades. Populações Tradicionais. Ação Política.

\section{Keywords}

Autonomy. Dialogue. Geograficidades, Traditional Populations. Political Action. 


\section{INTRODUÇÃO}

Este artigo nasce dos estudos, atividades e reflexões do Grupo de Pesquisa Costeiros, vinculado ao Programa de Pós-Graduação em Geografia da Universidade Federal da Bahia (UFBA). Com foco no manejo comunitário, na gestão territorial e nos conflitos socioambientais das Resex marinhas do estado da Bahia, observou-se ao longo de 10 anos de atuação do grupo que há diferentes situações de organização do tecido social das populações tradicionais dessas unidades, o que nos levou a observar influências negativas e positivas da gestão pública nos processos de criação e posterior gestão desses territórios. Todavia, percebeu-se também que reflexões críticas sobre a superação do modelo de cogestão estabelecido pelo Estado, inevitavelmente surgem durante o itinerário dos pesquisadores e nas experiências vividas por lideranças e membros dos conselhos e associações ligadas às Resex na Bahia.

Desde o ano de 2000, quando o governo brasileiro sancionou a Lei $\mathrm{n}^{\mathrm{o}}$ 9.985, que instituiu o Sistema Nacional de Unidades de Conservação (SNUC) e o Decreto $n^{\circ} 4340$, que em 2002, a regulamentou, as políticas ambientais passaram a usufruir de uma perspectiva jurídica que estabeleceu um modelo de preservação e conservação com evidente dimensão espacial-territorial. Os usos social e cultural da natureza passam a serem vistos como instrumentos de gestão e conservação da mesma e os valores e saberes locais, que caracterizam as populações tradicionais agroextrativistas, adquirem outra possibilidade de significação por parte da justiça e do Estado brasileiro. Importa ressaltar que as reservas extrativistas são frutos de conquista do movimento social seringueiro, liderado nas décadas de 1970 e 1980 - até seu assassinato - por Chico Mendes, o que imprime outra dimensão à criação do novo território legal.

Muito embora, até a data citada acima, registra-se inúmeros conflitos e lutas para que houvesse esse "avanço" na estrutura jurídica para as políticas ambientais no país, não significa que alcançamos uma situação ideal e que mais mudanças não sejam necessárias, tanto mudanças no que se refere às leis, seus conteúdos e sua operacionalidade, como o papel que o estado assumiu no modelo de cogestão proposto pela legislação atual.

No entanto, reconhece-se que o país passa por reformulações de suas leis, com a criação de perspectivas e instrumentos jurídicos que permitem propor a construção de ações de políticas públicas baseadas nos princípios de participação, cooperação e autonomia das populações tradicionais agroextrativistas. Assim, tornam-se imprescindíveis reflexões e análises acerca dos processos de planejamento e gestão e suas inter-relações com o manejo da natureza em 
territórios tradicionais. Estes são definidos no inciso II do art. $3^{\circ}$ do Decreto no 6.040, de 2007, que instituiu a Política Nacional de Desenvolvimento Sustentável dos Povos e Comunidades Tradicionais: "[...] espaços necessários à reprodução cultural, social e econômica dos povos e comunidades tradicionais, sejam eles utilizados de forma permanente ou temporária [...]” (BRASIL, 2007).

Diante do que o decreto citado acima estabeleceu, com forte ênfase à pluralidade e à diversidade social e cultural presente entre os diferentes territórios tradicionais, há o imperativo da diversidade também para a gestão e sua operacionalização. Nesse sentido, a legislação precisa passar por profundas reflexões e análises, pois, o seu texto não abrange a sociodiversidade inerente aos territórios em destaque e, portanto, não alcança suas demandas e anseios, que são também diversos.

Há a consciência de que o SNUC e todas as outras leis, decretos, resoluções, instruções normativas e portarias que delegam sobre criação, planejamento e gestão das Unidades de Conservação de Uso Sustentável (UCUS), representam significativas conquistas para as populações tradicionais agroextrativistas. Porém, a legislação por si só não garante as transformações necessárias. Nesse sentido, há a construção social demandada e inerente ao modelo de cogestão proposto pelas leis, mas além disso, também a superação da cogestão e a criação da autogestão, o que implicaria transcender os preceitos da legislação atual, seus objetivos, diretrizes e princípios.

Para tanto, admite-se ser necessário avanços teóricos, metodológicos e, sobretudo epistemológicos, por exigir quebras de paradigmas e ressignificação de conceitos e explicações científicas sobre o tema. A crise paradigmática que nos é revelada pelas ciências transcende os espaços acadêmicos e alcança os viveres sociais que são inevitavelmente influenciados pelas decisões científicas em relação aos diversos temas que compreendem nosso cotidiano. As teorias e as explicações científicas dominantes determinam os rumos do desenvolvimento e do progresso adotados em diferentes territórios. No caso do Brasil, a adoção do modelo neoliberal capitalista impõe caminhos econômicos e políticos que criam cenários desfavoráveis à transição de um modelo de cogestão das UCUS, controlado pelo Estado, para uma situação de autogestão controlada pela própria população com parcerias emancipatórias, e não regulatórias, com o Estado. Isso se explica, pois, dentre as características essenciais do modelo neoliberal capitalista, destaca-se a centralização das decisões e do controle do que é considerado recurso e/ou matéria-prima na natureza.

Considera-se aqui, portanto, que questões teóricas e epistemológicas legitimadas pelas ciências se desdobram em influências significativas para nosso 
cotidiano social e cultural. Os territórios tradicionais são também atingidos por tais influências, o que muitas vezes implica em obstáculos à percepção da relevância da autogestão e da necessidade de superar a cogestão primeiramente proposta. Segue-se com reflexões e análises acerca dos textos da legislação que versa sobre a gestão territorial das UCUS. A ênfase será dada a questões que se desdobram do paradoxo criado pela noção de cogestão estabelecida pelo Estado e o entendimento pautado em preceitos dialógicos e de autonomia social que nos remetem a um modelo de autogestão territorial.

\section{O SISTEMA NACIONAL DE UNIDADES DE CONSERVAÇÃO, A CHEFIA DO ESTADO E A COGESTÃO NOS TERRITÓRIOS TRADICIONAIS}

Todo o processo de luta e debates que culminou na assinatura da lei do SNUC em 2000 se desenvolveu, dentre outros, com destaque para a questão da autonomia individual e social das populações tradicionais agroextrativistas que ficariam como responsáveis pela gestão das unidades a serem criadas. No entanto, com a assinatura da lei, as noções de cogestão e corresponsabilidades foram adotadas e com o tempo a autogestão voltou às pastas das reivindicações desses grupos sociais.

Reconhece-se, todavia que a autogestão não depende somente do texto da legislação, pois se precisa de um processo de organização do tecido social para que o convívio cotidiano funda-se em tais princípios. Nesse ponto os saberes e seus fazeres adquirem funções essenciais ao processo. Aqui esse fazer é denominado de práxis, um “[...] fazer no qual o outro ou os outros são visados como seres autônomos e considerados como o agente essencial do desenvolvimento de sua própria autonomia" (CASTORIADIS, 1982. p. 94). A relação entre Estado e sociedade civil organizada pautar-se-ia no diálogo; nesse sentido, o diálogo aparece como algo intrínseco a esse processo e aos saberes e as experiências cotidianas que os criam e são por ele criadas; ele deve ser considerado como meio e fim,

O diálogo é este encontro dos homens, mediatizados pelo mundo, para pronunciá-lo, não se esgotando, portanto, na relação eu-tu. [...] Por isto, o diálogo é uma exigência existencial. [...] É um ato de criação (FREIRE, 2005, p. 91).

Para as populações tradicionais agroextrativistas, objetivos, princípios e diretrizes jurídicas sobre a gestão dos seus territórios, no contexto político

e econômico que vivenciamos atualmente, são, sobretudo, instrumentos 
de reivindicações e conquistas sociais e políticas; trata-se de projetos de transformações sociais emancipatórias.

O Estado estabeleceu como "chefe" das UC um funcionário do IBAMA que, a partir de 2007, com a assinatura da Lei no 11.516, foi substituído por um funcionário do então criado Instituto Chico Mendes para a Conservação da Biodiversidade (ICMBio) (BRASIL, 2007). A figura do chefe é representada por um funcionário, o qual é também o presidente do conselho deliberativo das UCUS. Isso cria um obstáculo jurídico para que um membro das populações tradicionais possa presidir o conselho e chefiar a unidade. Ora, se pensarmos sobre o significado simbólico da figura do "chefe"1 e seus possíveis desdobramentos nas relações cotidianas, corre-se o risco de construir obstáculos à emancipação das populações tradicionais agroextrativistas, no que tange à gestão territorial das unidades.

Nesse sentido, o domínio e o controle territorial ficam hegemonicamente ligados ao exercício do Estado. O conselho deliberativo (CD), regulamentado pela Instrução Normativa - IN no 02/2007, que disciplina diretrizes, normas e procedimentos para formação e funcionamento do CD de reserva extrativista (Resex) e reserva de desenvolvimento sustentável (RDS), é o órgão máximo de gestão das unidades. Vê-se no inciso I do art. $2^{\circ}$, da mesma IN, que o CD é entendido como um espaço legalmente constituído de valorização, discussão, negociação, deliberação e gestão da UC e sua área de influência referente a questões sociais, econômicas, culturais e ambientais.

$\mathrm{Na}$ composição do mesmo, o Estado admite a participação de grupos e/ou agentes sociais representando setores da economia que muitas vezes não têm a conservação da natureza como propósito. Quando o tema amplia-se para a conservação e a valorização de saberes e práticas cotidianas tradicionais, os propósitos podem se distanciar ainda mais. As populações tradicionais agroextrativistas e suas economias locais não apresentam características e/ou dinâmicas com condições de atender plenamente os anseios do capital privado e do consumo das sofisticadas tecnologias atuais. Todavia, isso cria um abismo entre os interesses e as demandas sociais das populações tradicionais e os interesses econômicos e mercadológicos de grandes grupos empresariais e/ou financeiros.

Tem-se, portanto, um cenário em que as decisões não são tomadas exclusivamente pelas populações tradicionais, com, muitas vezes, outros interesses envolvidos que podem não ser os mesmos interesses de conservação e melhorias nas condições de vida dos moradores-usuários das UCUS. Tal cenário coloca em xeque as diretrizes que devem ser consideradas na formação e funcionamento

\footnotetext{
Dicionários diversos definem a palavra chefe como aquele que governa, comanda e dirige, ou a pessoa que ocupa o posto superior dentro de uma determinada hierarquia.
} 
do CD e que são listadas entre os incisos I - XII do art. $3^{\circ}$ da IN nº 02/2007 (BRASIL, 2007). Sendo assim, as populações tradicionais são compelidas a formar consensos internos para que suas ideias sejam levadas em consideração; caso contrário, a criação de uma esfera de decisão mais ampla, abarcando um leque variado de agentes locais, pode ser realizada em detrimento dos extrativistas. O Centro Nacional de Populações Tradicionais e Desenvolvimento Sustentável (CNP'T), vinculado ao ICMBio, recomenda que os extrativistas de Resex constituam uma associação mãe de modo a proporcionar outra esfera de decisão interna, contudo esse encorajamento frequentemente não se confirma nas UC por razões diversas (ex: falta de preparação dos funcionários a lidar com pessoas, prioridades governamentais em favor do dito desenvolvimento econômico, participação falha dos extrativistas nos CD, ritmos de ações do ICMBio que não condizem com as prioridades locais etc.).

Portanto, o CD tem condições plenas de interferir efetivamente na elaboração do principal documento de gestão da unidade: o plano de manejo. Segundo a IN no 01/2007, que disciplina diretrizes, normas e procedimentos para a elaboração do plano de manejo em Resex e RDS, há a garantia da participação efetiva das populações tradicionais no processo, porém, as decisões finais sobre seu conteúdo, restrições e normas são deliberadas em plenária do CD, no qual não há votos somente das populações tradicionais (BRASIL, 2007).

Os exemplos vivenciados durante as atividades do Grupo de Pesquisa Costeiros, no que refere à gestão das Resex marinhas na Bahia, mostram que conflitos nascem e são intensificados justamente pelo fato de haver entre os integrantes do órgão máximo de gestão das unidades, o $\mathrm{CD}$, membros que defendem um modelo de crescimento econômico com avanços tecnológicos, contraditórios com os modos de vida que ocorrem nessas Resex.

Há, por exemplo, na Resex marinha Baía do Iguape conflitos sociais relevantes há pelo menos uma década e que foram motivados pela presença $a$ priori do Grupo Votorantim, beneficiária da concessão pública para exploração da Usina Hidroelétrica de Pedra do Cavalo, e posteriormente do governo federal com a instalação do Polo Naval no distrito de São Roque em Maragogipe, um dos municípios nos quais se estende a Resex. Outros exemplos que podemos destacar e que também foram observados durante estudos e pesquisas do Grupo de Pesquisa Costeiros são os conflitos entre, de um lado, o mercado hoteleiro e O poder público municipal de Canavieiras, e de outro lado, os pescadores e marisqueiras que lideraram a criação da Resex marinha de Canavieiras.

Ao resgatar o histórico de lutas dos seringueiros e povos da floresta para alterações na legislação ambiental e inclusão do uso social e cultural da natureza 
como instrumento de gestão e conservação, percebe-se que havia debates e discursos que colocavam a autonomia administrativa como princípio e fim para a gestão das áreas destinadas as populações tradicionais agroextrativistas. Em sua tese de doutoramento, Claudia C. Cunha (2010) reconhece a abertura do Estado brasileiro para o debate sobre o modelo de gestão das Resex.

No entanto, destaca mudanças institucionais que reconfiguraram a dinâmica institucional do poder local e redefiniram o sentido da autonomia anteriormente adotado pelos movimentos sociais envolvidos no processo. Contudo, a autora registra o processo de gênese das reservas extrativistas, mostrando como o movimento foi, em razão do apoio forte de ambientalistas e das perspectivas de avanços legais, dando mais ênfase à bandeira ambiental em detrimento da de reforma agrária. Em decorrência, as populações tradicionais seringueiras (e depois pesqueiras) conquistaram territórios legais, mas submetidos a uma série de regras determinadas pelo Estado, perdendo assim o processo inicial de autogestão de seus territórios tradicionais em favor da cogestão, com presidência do CD e a chefia das Resex nas mãos do representante do Estado, o ICMBio. A ação política foi em consequência reduzida a um conjunto de técnicas e procedimentos institucionais estabelecidos por meio do Plano de Manejo da unidade.

Assim, ao tentar reduzir a ação a um conjunto de técnicas e procedimentos receitados, pode-se aqui criar um paralelo com as reflexões de Arendt (2014) sobre os processos de substituição da ação pela fabricação, o que considera contra a democracia e uma negação dos elementos essenciais da política. No tocante às UCUS, o que está em xeque é o modelo e O conceito de governo “[...] isto é, a noção de que os homens só podem viver juntos, de maneira legítima e política, quando alguns têm o direito de comandar e os demais são forçados a obedecer" (ARENDT, 2014, p. 277); a ação passa a ser então uma mera execução de ordens.

Para a gestão comunitária das UCUS, com esse preceito jurídico da chefia do CD e da UCUS ser um representante do Estado e não um moradorusuário da unidade, cria-se um cenário desfavorável à construção da autonomia administrativa e financeira, o que implica na necessidade da presença eterna de agentes do poder público no controle do território.

\section{DA COGESTÃO À AUTOGESTÃO EM TERRITÓRIOS TRADICIONAIS: MANEJO COMUNITÁRIO, DIÁLOGO DE SABERES E AUTONOMIA PARA A AÇÃO POLÍTICA}

Como foi mencionado anteriormente, considera-se a autonomia um fenômeno da vida social e política e o seu estudo pode evidenciar características 
das relações entre gestão pública e gestão comunitária, no que se refere ao manejo das UCUS no país. Intimamente ligada aos saberes e fazeres (práxis), há no processo de sua construção (autonomia social e individual) uma necessidade inerente da valorização dos saberes e fazeres do outro, pois, disso prescinde o diálogo. Não há efetivação da autonomia num contexto onde não haja diálogo, pois, ela "[...] é instauração de outra relação entre o discurso do Outro e o discurso do sujeito.” (CASTORIADIS, 1982, p. 126). Essa reflexão nos conduz a admitir que a autonomia só pode ser desejada para todos e sua efetivação só se concebe plenamente enquanto empreitada coletiva (CASTORIADIS, 1982).

Se o diálogo é um ato de criação (FREIRE, 2005),

[...] na práxis a autonomia dos outros não é um fim, ela é, sem jogo de palavra, um começo, [...] ela não é finita, não se deixa definir por um estado ou características quaisquer. Existe relação interna entre o que é visado (o desenvolvimento da autonomia) e aquilo por que ele é visado (o exercício da autonomia), são dois momentos de um processo; [...] a práxis jamais pode reduzir a escolha de sua maneira de operar a um simples cálculo; não que este fosse muito complicado, mas porque, por definição, deixaria escapar o fator principal - a autonomia (CASTORIADIS, 1982, p. 95).

Por isso, do diálogo se espera a cumplicidade e a cooperação e, portanto, a competição de ideias é substituída pela partilha de ideias, saberes e experiências. As ações do Estado que se fundam nos preceitos da investigação científica e social poder-se-iam desenvolver enquanto formas solidárias de participação. A ação torna-se um processo de "[...] criação solidária de saberes sociais em que a palavra-chave não é o próprio conhecimento, mas é, antes dele, o diálogo" (BRANDÃO; STRECK, 2006, p. 13).

Aqui se resgatam as reflexões de Paulo Freire (2011) no livro "Extensão ou comunicação?", no qual há um debate sobre o sentido e o fundamento das ações do Estado no que tange à extensão rural, entendida como apoio científicotécnico e de gestão, que o poder público direciona especificamente à população rural. Daí o destaque à comunicação: “[...] o mundo social e humano, não existiria como tal se não fosse um mundo de comunicabilidade fora do qual é impossível dar-se o conhecimento humano" (FREIRE, 2011, p. 85). O ato do conhecimento, que é um ato intencional, dá-se numa relação dialógica com o mundo e entre agentes políticos participantes do processo.

A parceria com o Estado na gestão das UCUS demanda ser emancipatória e não regulatória. Nesse sentido, as atividades de extensão do ICMBio deveriam ser, portanto, ações de quem estende conhecimento e experiência até alguém. No entanto, Freire (2011) chama a atenção para o risco da extensão não se limitar 
a um processo de messianismo, invasão cultural e/ou manipulação promovidos pelo Estado.

Não lhe cabe, portanto, de uma perspectiva realmente humanista, estender suas técnicas, entregá-las, prescrevê-las; não lhe cabe persuadir nem fazer dos camponeses o papel em branco para sua propaganda.

Como educador, se recusa a "domesticação" dos homens, sua tarefa corresponde ao conceito de comunicação, não ao de extensão (FREIRE, 2011, p. 23).

A distinção que Paulo Freire (2011) faz entre comunicação e extensão admite a relevância das técnicas, mas a ação e o diálogo são essenciais ao processo. Como ocorre com o fenômeno da autonomia, no caso da ação, a coletividade e a pluralidade humana são também princípios intrínsecos. "Ao agir e falar, os homens mostram quem são, revelam ativamente suas identidades pessoais e únicas, e assim fazem seu aparecimento no mundo humano [...]" (ARENDT, 2014, p. 224).

Entender que nossa existência no mundo é também uma existência com o mundo (FREIRE, 2002) é para a ação um fator imprescindível em sua efetivação cotidiana. É a partir desse pressuposto que nos tornamos “[...] capazes de realizar a complexa operação de, simultaneamente, transformando o mundo através de sua ação, captar a realidade e expressá-la por meio de sua linguagem criadora" (FREIRE, 2002, p. 77). O agir e o falar humanos evidenciam o nosso existir enquanto um modo de vida que nos é próprio.

Nesse sentido, considera-se o sujeito enquanto agente de sua própria transformação; daí o papel das relações dialógicas para a autonomia. Isso se dá na ação política e no contexto social necessário ao seu desenvolvimento. O espaço da aparência citado por Arendt (2014) como sendo o espaço que passa a existir sempre que os seres humanos se reúnem "[...] na modalidade do discurso e da ação [...]. Onde quer que as pessoas se reúnam, esse espaço existe potencialmente, mas só potencialmente, não necessariamente nem para sempre" (ARENDT, 2014, p. 249). Por isso a ênfase foi dada anteriormente à organização do tecido social nos espaços da vida cotidiana de populações tradicionais agroextrativistas.

Em base nesse pressuposto, entende-se que a verdadeira transformação passa pela efetiva delegação de poder do Estado para essas populações tradicionais, o que se traduz, por exemplo, pela escolha, em cada Resex, de um coordenador oriundo da própria população extrativista, apoiado por uma direção e demais instâncias de organização (ex: CD, conselhos fiscais e outros) compostas também por extrativistas. O próprio grupo Costeiros pôde verificar o amadurecimento social e político de lideranças comunitárias na medida em que se engajam em cargos de responsabilidade, confirmando o quanto a práxis 
política constitui uma escola para quem se engaja nela. Lembra-se também que a gestão e o planejamento comunitários podem incluir nos seus processos erros de gestão, mas estes não são considerados aqui como obstáculos ou motivação para punições e sim como possibilidades de aprendizagem e melhoria, a partir da observação e análise dos erros (SANTOS, 2008). Com a assinatura do Decreto no 6040/2007 que institui a Política Nacional de Desenvolvimento Sustentável dos Povos e Comunidades Tradicionais e criou, assim, uma perspectiva jurídica ao conceito de territórios tradicionais, o Brasil reconheceu juridicamente a relevância de tais espaços, independentemente da criação ou não de alguma UCUS.

Como o decreto citado acima considera os territórios tradicionais enquanto espaços para a reprodução social, cultural e econômica das populações tradicionais agroextrativistas, há intrínseco na noção adotada, significados simbólicos atribuídos pelas comunidades aos seus espaços de vivência e experiência cotidianas e, portanto, valores que sustentam e caracterizam determinada comunidade e que precisam ser contemplados durante os processos de gestão dessas áreas. "A natureza apresentase imediatamente ao conhecimento desses grupos como um lugar de permanente observação, pesquisa e reprodução de saberes" (CASTRO, 1998, p. 7). Isso nos indica haver entre essas populações um profundo e complexo conjunto de saberes sobre o mundo em que eles vivem e habitam.

As formas simbólicas e os significados atribuídos nascem de relações e sentires íntimos entre o ser e o mundo. Todo o valor afetivo do ser para com o espaço aparece nas e a partir das experiências vividas e dos sentidos. Essas experiências, aliadas aos sentidos, são os meios pelos quais os seres humanos constroem suas realidades (TUAN, 2013). Toda essa trama de relações sociais cotidianas evidencia-nos as geograficidades de um determinado grupo social. A essa geograficidade está ligada a dimensão espacial da vida humana, que no caso das populações tradicionais agroextrativistas aparecem e se evidenciam nos denominados territórios tradicionais. É como disse Moreira (2012, p. 178) o “[...] ser do espaço: a geograficidade".

Assim, faz-se essencial entender o sentido geográfico dos territórios tradicionais, o qual pode ser revelado e analisado por meio do estudo das geograficidades de seus usuários-moradores. Pois, se a geograficidade é o fenômeno espacial que liga os seres humanos ao seu processo de ser e estar no mundo, ou seja de habitá-lo, "[...] como modo de sua existência e seu destino" (DARDEL, 2011, p. 2), as experiências vividas apresentam-se essenciais à percepção e ao entendimento do contexto social e político de cada território em questão. Daí a afirmação anterior de que, ao falar e agir, o ser humano mostra quem é e aparece ao mundo humano (ARENDT, 2014). 
Essas realidades cognitivas e afetivas que ligam cada ser humano ao mundo que ele habita, são, pois, a realidade geográfica de cada um, “[...] o lugar onde ele está, os lugares de sua infância, o ambiente que atrai sua presença. Terras que ele pisa ou onde trabalha, o horizonte do seu vale, ou a sua rua, o seu bairro, seus deslocamentos cotidianos [...]" (DARDEL, 2011, p. 34). No caso dos territórios tradicionais, isso não é diferente, sobretudo por haver entre as comunidades tradicionais agroextrativistas práticas sociais e culturais onde a partilha de saberes e a troca de experiências estão presentes no cotidiano.

O espaço é aqui “[...] a dimensão do social: da coexistência contemporânea de outros" (MASSEY, 2013, p. 15), corroborando com princípios inerentes à ação política e a autonomia, tais como a pluralidade humana e o diálogo de saberes. Prosseguindo com as reflexões de Massey (2013), o espaço apresenta-se como a esfera que possibilita a existência da multiplicidade, onde distintas trajetórias coexistem na multiplicidade e num ambiente em constante construção.

Certamente é parte do meu argumento que não apenas o espacial é político, (o que, depois de muitos anos e do muito que foi escrito a respeito, pode ser tido como dado), mas que, sobretudo, pensar no espacial de um modo específico pode perturbar a maneira em que certas questões políticas são formuladas, pode contribuir para argumentações políticas já em curso e - mais profundamente - pode ser um elemento essencial na estrutura imaginativa que permite, em primeiro lugar, uma abertura para a genuína esfera do político (MASSEY, 2013, p. 29-30).

Daí a relevância que tem o Estado considerar essencial a geograficidade das populações tradicionais agroextrativistas ao pensar e agir sobre a gestão dos seus espaços. A ideia de ação política para a autonomia (ARENDT, 2014; CASTORIADIS, 1982) coloca a pluralidade humana e a possibilidade eterna do novo como preceitos necessários à autogestão territorial. Aqui se trata de pensar uma política que seja sensível às características e particularidades de cada espaço e de cada grupo de populações tradicionais agroextrativistas que o habita.

Admite-se, portanto, que o manejo comunitário somente é realizável a partir dos pressupostos do diálogo de saberes e da autonomia para a ação política. Como a ação é a única atividade humana que ocorre sem a mediação da técnica e/ ou dos objetos, os encontros que ela nos possibilita enaltecem nossa pluralidade intrínseca (ARENDT, 2014). Entende-se, portanto, que a diversidade social e cultural não precisa ser posta na perspectiva do obstáculo, pois, a dialogicidade e a ação prescindem do contrário: sem o outro enquanto sujeito na relação não há diálogo e nem emancipação social e política. "Desta forma, consciência de e ação sobre a realidade são inseparáveis constituintes do ato transformador pelo qual homens e mulheres se fazem seres de relação" (FREIRE, 2002, p. 78). 
O debate reflexivo frente aos significados semânticos e políticos atribuídos à extensão e à comunicação, que Paulo Freire (2011) nos coloca, indica a necessidade da revisão no modelo de gestão que as normatizações jurídicas estabeleceram para as UCUS. Há um imbróglio jurídico, entre diretrizes e princípios legais que apontam para a parceria emancipatória entre Estado e populações tradicionais agroextrativistas, e determinações hierárquicas institucionais que criam contradições na gestão das UCUS no país ao nomear, por exemplo, um analista ambiental do ICMBio, e não um morador-usuário, como "chefe" da unidade e presidente do CD.

As populações tradicionais agroextrativistas desempenham o papel dos trabalhadores sociais nos processos de mudanças (FREIRE, 2002). Fazer do trabalhador social um agente de sua própria mudança, como bem ressalva Freire (2002), não pode ser considerado um simples clichê, mas, sobretudo um desafio.

Para os seres humanos, como seres da práxis, transformar o mundo, processo em que se transformam também, significa impregná-lo de sua presença criadora, deixando nele as marcas do seu trabalho (FREIRE, 2002, p. 81).

Assim, essa atuação sobre a realidade a fim de transformá-la é realizada de acordo com a organização do tecido social e das geograficidades locais. Pois, o mundo humano é socialmente construído e instituído pelo e no imaginário com suas instituições e convenções para a sociabilidade (CASTORIADIS, 1982). Ao mesmo tempo, o mundo humano é também constituído de técnicas e objetos técnicos com materialidades, significados e usos atribuídos. Há, portanto, os saberes, os sentires, os fazeres e os objetos fruto do trabalho e que aparecem como obra humana que compõe um mundo exclusivamente humano (TUAN, 2013; ARENDT, 2014; FREIRE, 2011).

Há, portanto, uma relação comunicativa entre sujeito cognoscente com o universo cognoscível. "O mundo humano é dessa forma, um mundo de comunicação.” (FREIRE, 2011, p. 86). Nesse caso, a dialogicidade, junto com a política, é fenômeno da vida social humana que nos diferencia de outros sistemas vivos que simplesmente estão no mundo,ora, não objetivando-o, não há consciência de estar com o mundo (FREIRE, 2002).

Para a ação política, a autonomia, o diálogo e a consciência de ser no mundo e com $o$ mundo são essenciais. Para isso, é atribuída a necessidade de uma relação dialógica-comunicativa entre agentes participantes do processo, no presente caso, a gestão das UCUS. O papel do ICMBio, que demanda ser emancipatório, abandonaria a noção usual de extensionista e passaria a adotar a noção apresentada por Freire (2011) para comunicação fundamentada no humanismo. 
Humanismo que, recusando tanto o desespero quanto o otimismo ingênuo, é, por isso, esperançosamente crítico. E sua esperança crítica repousa numa crença também crítica: a crença em que os homens podem fazer e refazer coisas; podem transformar o mundo. Crença em que, fazendo e refazendo as coisas e transformando o mundo, os homens podem superar a situação em que estão sendo um quase não ser e passar a ser um estar sendo em busca do ser mais (FREIRE, 2011, p. 99-100).

A parceria entre ICMBio e populações tradicionais agroextrativistas precisa ser mantida. No entanto, essa parceria demanda adquirir, enquanto aspecto fundamental que a justifica, um caráter essencialmente emancipatório e libertário, pois, essas populações se compõem de agentes políticos que exercem papéis de sujeitos das suas próprias histórias.

Para tanto, entende-se ser necessário alterações nos instrumentos jurídicos que estabelecem diretrizes e normas técnicas ao modelo de gestão das UCUS. Pois, há uma determinação jurídica que coloca o analista do ICMBio enquanto chefe das unidades. Outro ponto que precisaria ser repensado pelo Estado, são as estratégias de repasse de verbas e o pagamento de demandas comuns as responsabilidades e ações do presidente e do funcionamento de um escritório do ICMBio dentro de uma UCUS. Hoje o Estado é responsável pela infraestrutura necessária ao funcionamento desses escritórios e de todas as demandas ligadas ao exercício das funções do chefe e da equipe (quando há) de funcionários responsáveis diretamente pela administração. Portanto, a autogestão não significaria repassar toda essa demanda financeira e administrativa para os beneficiários das UCUS. Trata-se sobretudo, da autonomia na gestão do território que lhe foram concedidos ${ }^{2}$.

\section{CONSIDERAÇÕES FINAIS}

Ao analisar o processo de gênese - da criação à implantação das reservas extrativistas com a conclusão da institucionalização pelo SNUC -, percebese que se passou de uma conquista do movimento social seringueiro que administrava seus territórios em autogestão a uma cogestão, com forte controle

\footnotetext{
O documento denominado Contrato de Concessão de Direito Real de Uso (CCDRU) é que dá aos beneficiários das UCUS totais condições de decidirem sobre o uso e a gestão do território que delimita cada unidade. É o Contrato Administrativo que transfere direitos reais da propriedade. Prevista no Decreto-Lei n⿳⺈ 271/1967 e na Lei nº 9.636/1998 (que prevê sua aplicação para os terrenos da União) poderá ser aplicada nos casos previstos em terrenos de marinha e acrescidos - áreas inalienáveis; em áreas vazias destinadas à provisão habitacional; em áreas ocupadas, sujeitas à pressão imobiliária ou em áreas de conflito fundiário; no uso sustentável das várzeas e para a segurança da posse de comunidades tradicionais; e para fins comerciais. Disponível em: Site do Ministério do Planejamento. Acesso em: 30 abr. 2015.
} 
governamental. Ora, com um Estado que - qualquer seja sua coloração política - se caracteriza por sua ideologia desenvolvimentista, o órgão ambiental se encontra pressionado de modo contraditório entre a defesa dos interesses das populações tradicionais e as diretrizes de crescimento econômico, que são sistematicamente contrárias à preservação ambiental e à manutenção de modos de vida diferentes da sociedade capitalista.

Em que pese essa contradição, percebe-se que o cerne do problema está no compartilhamento da gestão territorial entre o poder público e a população. Como observado no artigo, apesar do avanço na legislação ambiental ao reconhecer a importância das populações tradicionais na preservação ambiental, a institucionalização da conquista do movimento social foi erodindo a conquista do movimento social, limitando-a de acordo com outras prioridades, de natureza econômica. Isso configura um retrocesso do ponto de vista do movimento social, mas que pode ser revertido de novo, de acordo com os princípios fundadores das Resex, ou seja, de reconhecer as populações tradicionais como cruciais para a proteção ambiental graças aos seus saberes ambientais tradicionais.

Contudo, para tal, se faz necessário repensar a prática do Estado na gestão das UCUS no sentido de gerenciar com diálogo e com a criação de um cenário para a organização do tecido social voltada à autonomia das populações tradicionais agroextrativistas, beneficiárias das UCUS. Trata-se de uma parceria emancipatória e não de controle do território. Nesse sentido, entende-se necessário transformações jurídicas, normativas, políticas e de significados atribuídos à gestão pública.

Com o amadurecimento da organização comunitária, pode se encarar a possibilidade de ter no ICMBio, não mais um órgão de direção das UCUS, mas um parceiro institucional que atuaria na fiscalização ambiental - demanda crônica entre as comunidades pesqueiras - e mal atendida e como assessor técnico a serviço das associações de usuários das Resex. O que se questiona não é a parceria em si, mas a maneira como ela foi sendo moldada pelas legislações e práticas do Estado e a influência na criação de cenários desfavoráveis ao cumprimento das funções sociais, políticas e econômicas pelas quais as UCUS são criadas.

\section{REFERÊNCIAS}

ARENDT, H. A condição humana. 11. ed. Tradução de Roberto Raposo. Rio de Janeiro: Forense Universitária, 2014. 407p. 
BRANDÃO, C. R.; STRECK, D. R. A pesquisa participante e a partilha do saber: uma introdução. In: BRANDÃO, C. R.; STRECK, D. R. (Org.). Pesquisa participante: o saber da partilha. 2. ed. Aparecida-SP: Ideias e Letras, 2006. p. $7-20$.

BRASIL. Decreto $\mathbf{n}^{\circ} \mathbf{6 0 4 0}$ de 2007. Institui a Política Nacional de Desenvolvimento Sustentável dos Povos e Comunidades Tradicionais. Brasília, 2007.

Lei $\mathbf{n}^{\circ} \mathbf{1 1 5 1 6}$ de 2007. Dispõe sobre a criação do Instituto Chico Mendes de Conservação da Biodiversidade; altera as Leis $n^{\circ} 7.735$, de 22 de fevereiro de 1989, 11.284, de 2 de março de 2006, 9.985, de 18 de julho de 2000, 10.410, de 11 de janeiro de 2002, 11.156, de 29 de julho de 2005, 11.357, de 19 de outubro de 2006, e 7.957, de 20 de dezembro de 1989; revoga dispositivos da Lei no 8.028, de 12 de abril de 1990, e da Medida Provisória no 2.216-37, de 31 de agosto de 2001; e dá outras providências. Brasília, 2007.

Instrução normativa $\mathbf{n}^{\circ} 02$ de 2007. Disciplina as diretrizes, normas e procedimentos para formação e funcionamento do Conselho Deliberativo de Reserva Extrativista e de Reserva de Desenvolvimento Sustentável. Brasília, 2007.

Instrução normativa $\mathbf{n}^{\circ} 01$ de 2007. Disciplina as diretrizes, normas e procedimentos para a elaboração de Plano de Manejo Participativo de Unidade de Conservação Federal das categorias Reserva Extrativista e Reserva de Desenvolvimento Sustentável. Brasília, 2007.

Decreto $\mathbf{n}^{\circ} \mathbf{4 3 4 0}$ de 2002. Regulamenta o Sistema Nacional de Unidades de Conservação. Brasília, 2002.

CASTORIADIS, Cornelius. A instituição imaginária da sociedade. $5^{\mathrm{a}} \mathrm{ed}$, Tradução de Guy Reynaud. Rio de Janeiro: Paz e Terra, 1982. 418p.

CASTRO, Edna. Território, biodiversidade e saberes de populações tradicionais. Paper do NAEA, Belém, n. 92, p. 3-16, 1998.

CUNHA, C. C. Reservas Extrativistas: institucionalização e implementação no Estado brasileiro dos anos 1990. 2010, 308f. Tese (Doutorado em Psicossociologia de Comunidades e Ecologia Social - EICOS) - Instituto de Psicologia, Universidade Federal do Rio de Janeiro, Rio de Janeiro, 2010.

DARDEL, E. O homem e a Terra: natureza da realidade geográfica. Tradução: Werther Holzer. São Paulo: Perspectiva, 2011. 159p.

FREIRE, P. Extensão ou comunicação? 15. ed. Tradução: Rosiska Darcy de Oliveira. São Paulo: Paz e Terra, 2011. 131p. 
A pedagogia do oprimido. 41. ed. Rio de Janeiro; Paz e Terra, 2005. $213 p$.

Ação cultural para a liberdade. 10. ed. São Paulo: Paz e Terra, 2002. $176 \mathrm{p}$.

FEARNSIDE, P. M. The evolving context of Brazil's environmental policies in Amazonia. Belém, Novos Cadernos NAEA. Vol. 16, n. 2 p. 9-25, jul-dez 2013.

MASSEY, D. Pelo espaço: uma nova política da espacialidade. 4. ed. Tradução de Hilda Pareto Maciel e Rogério Haesbaert. Rio de Janeiro: Bertrand Brasil, 2013. 312p.

MOREIRA, R. Geografia e práxis: a presença do espaço na teoria e na prática geográficas. São Paulo: Contexto, 2012. 221p.

PROST, C. Resex marinha versus polo naval na Baía do Iguape - BA, Belém, Novos Cadernos NAEA, UFPA/NAEA, Vol. 13, n. 1, jan-jun 2010, pp. 47-70 SANTOS, M. A experiência vivida na reserva extrativista marinha Baía do Iguape/BA: diálogo de saberes, planejamento, educação e autonomia. Caminhos da Geografia, v. 9, n. 27, p. 1-16, set. 2008.

TUAN, Y. Espaço e lugar: a perspectiva da experiência. Tradução de Lívia de Oliveira. Londrina: Eduel, 2013. 247p. 